\title{
(O) CPP/) Anaesthesiology \\ COMPARISON OF INTRATHECAL DEXMEDETOMIDINE AND MAGNESIUM SULPHATE AS AN ADJUVANT TO 0.5\% HYPERBARIC BUPIVACAINE IN LOWER LIMB SURGERY
}

\section{Shaheer Ahmed Siddiqui* \\ Kapil Rastogi \\ Aamir Laique \\ Khan \\ ABSTRACT}

Assistant Professor, Department of Anaesthesiology, Integral Institute of Medical Science and Research, Lucknow. *Corresponding Author

Assistant Professor, Department of Anaesthesiology, Integral Institute of Medical Science and Research, Lucknow. Assistant Professor, Department of Anaesthesiology, Integral Institute of Medical Science and Research, Lucknow.

Background: Epidural anesthesia is commonly used for perioperative as well as postoperative analgesia in lower limb surgeries. Adjuvant in spinal anesthesia prolongs the duration of anesthesia as well as postoperative analgesia. In this study we evaluate the effects of intrathecal dexmedetomidine and magnesium sulfate as an adjuvant to $0.5 \%$ hyperbaric bupivacaine in lower limb surgeries.

Methods: Total 60 patients belonging to ASA I or II aged 24 to 57 years of either sex were included in this study and randomly distributed into two groups. Group $(\mathrm{B}+\mathrm{M})$ received intrathecal 100mg magnesium sulfate and Group $(\mathrm{B}+\mathrm{D})$ received intrathecal 5.0 mcg dexmedetomidine with hyperbaric bupivacaine $15 \mathrm{mg}(3 \mathrm{ml}$ of $0.5 \%)$. Onset and duration of sensory and motor block, duration of analgesia, hemodynamic changes and complications were recorded.

Results: The mean Onset time of sensory block at T10 ( $m i n$.), Time to maximum sensory block level (min.), Time in minutes for complete motor block (min.), Time for Motor Emergence from Bromage 3 (min.), Time for Sensory Emergence and Time for first analgesia (min) were significantly different between groups.

Conclusion: The dexmedetomidine as an adjuvant with hyperbaric bupivacaine leads to earlier onset and prolonged duration of both sensory and motor block as compared to magnesium sulfate.

KEYWORDS : Intrathecal, Bupivacaine, Dexmedetomidine, epidural block, magnesium

\section{INTRODUCTION}

Pain is an unpleasant feeling that begins from continuous and approaching tissue harm. Epidural is the safe and effective anaesthesia providing intra-operative and postoperative analgesia. Till day, no drug has been distinguished that explicitly represses nociception without related side effects [1]

Epidural anesthesia is the most frequently used technique for perioperative as well as post-operative analgesia in lower limb surgeries [2]. Quick postoperative mobilization and rehabilitation with essentially associated pain and distress is the best component in present day orthopaedic surgery [3-5]. Many a period for accomplishing wanted peri-operative sedative impact, constantly enormous volumes of local anaesthetics are utilized, in this way expanding the potential outcomes of nearby sedative harmfulness and malicious haemodynamic results.

Various recent studies reported that the utilization of intrathecal adjuvants has prolong the duration of block, increased the successes rate, patient satisfaction, faster recovery and diminished the asset use compared with general anaesthesia. The nature of spinal anaesthesia has been improve with the addition of opioids such as morphine, fentanyl, and sufentanil and different medications like ketamine, midazolam, dexmedetomidine, clonidine and magnesium sulphate [6]. Recent studies suggest the role of magnesium sulfate as an adjuvant to local anesthetics in spinal anesthesia [3]. The biological basis for potential antinociceptive effect of magnesium is its voltage-dependent regulation of calcium influx into the cell, and noncompetitive antagonism of N-methyl-D-aspartate (NMDA) receptors [1].

Recent studies demonstrated that the magnesium sulfate as an adjuvant to bupivacaine in spinal anesthesia can play a beneficial role also in spinal anesthesia [7-9]. It acts by blocking N-methyl-D-aspartate (NMDA) channels in voltage dependent fashion and can prevent the induction of central sensitization by peripheral nociceptive stimulation [10].

Dexmedetomidine is agonist of alpha-2 adrenergic receptors used as adjuvants in epidural to increase the analgesic duration [11]. Dexmedetomidine is indicated for sedation of critically ill or injured patients in an intensive care unit setting [12]. It has also been used intravenously for postoperative pain relief as adjunct to epidural bupivacaine [13]. Intrathecal and epidural characteristics of dexmedetomidine have been studied in animals $[14,15]$. In this study we aim to evaluate the efficacy of magnesium and dexmedetomidine as an adjuvant to epidural bupivacaine in lower limb surgery.

\section{MATERIALS AND METHODS}

This prospective observational study was conducted in the department of Anaesthesiology, Integral Institute of Medical Science and Research, Lucknow, India. Total 60 patients with 24-57 years age, ASA grade I or II scheduled for elective lower limb surgeries were included in this study. Patients with chronic pain syndrome, history of analgesic use, history of adverse reaction to any study medication and neurologic disorders were excluded from the study. Informed written consent was obtained from all the participants after ethical approval from Institutional Ethical Committee.

All patients were divided into two groups of equal size on computer generated random table.

Group (B+M): Spinal anaesthesia with hyperbaric bupivacaine $15 \mathrm{mg}$ (3ml of $0.5 \%)+$ intrathecal $100 \mathrm{mg}$ magnesium sulfate

Group (B+D): Spinal anaesthesia with hyperbaric bupivacaine $15 \mathrm{mg}$ $(3 \mathrm{ml}$ of $0.5 \%)+$ intrathecal $5.0 \mathrm{mcg}$ dexmedetomidine

All patients were premedicated with ranitidine $150 \mathrm{mg}$, metoclopramide $10 \mathrm{mg}$ and alprazolam $0.25 \mathrm{mg}$ orally, night before surgery. Every one of them was appropriately guided to make them mindful with respect to the way toward giving spinal anaesthesia. In the operation theatre (OT), all patients were associated with electrocardiogram, oxygen immersion $\left(\mathrm{SpO}_{2}\right)$ and noninvasive pulse monitor and all the basal parameters were recorded and an IV line was gotten with 18 gauge cannula on the dorsum of hand and all patients were preloaded with $10-15 \mathrm{ml} / \mathrm{kg}$ of Ringer Lactate.

Lumbar cut was performed utilizing aseptic procedures in the sitting situation through the L4-L5 interspace in the midline utilizing 25-G Quincke needle, the tip of which was held corresponding to the dural filaments. At the point when clear cerebrospinal liquid was noticed, $15 \mathrm{mg}$ of $0.5 \%$ hyperbaric bupivacaine was controlled into the subarachnoid space. Every patient was then brought to the supine position and the operation table was held level with cushion under the head. Supplemental oxygen was given to each patient at 5 litre/minute. Subsequent to continuing supine position the patients in group $(B+M)$ got intrathecal mixture of magnesium sulfate in 100 normal saline and 
Volume - 11 | Issue - 01 | January - 2021 | PRINT ISSN No. 2249 - 555X | DOI : 10.36106/ijar

group (B+D) got intrathecal mixture of dexmedetomidine in $100 \mathrm{ml}$ normal saline. The rate infusion was kept at 10 macro drops $/ \mathrm{min}$ in both study groups.

The heart rate, blood pressure and oxygen saturation were continuous monitor and recorded at every $5 \mathrm{~min}$ for first $30 \mathrm{~min}$, at every $10 \mathrm{~min}$ for next $30 \mathrm{~min}$ and at every $15 \mathrm{~min}$ until the end of the surgery and during shifting in both groups, pre and intra-operatively. Hypotension has been characterized as systolic blood pressure $>30 \%$ decline in baseline . In tachycardia, the heart rate $>100 / \mathrm{min}$ and in bradicardia $<60 / \mathrm{min}$ and these patient was treated with injection atropine $0.6 \mathrm{mg}$ IV. Sensory block was assessed bilaterally by using analgesia to pin prick in midclavicular line. The time to reach the maximum level of sensory block and time for regression of two segments in the maximum block height was noted. Motor blockade was assessed by using Bromage scale ( 0 : no motor block; 1 : inability to raise extended legs; 2 : inability to flex knees; 3 : inability to flex ankle joints). The level of sensory and motor blockade was checked every 2 min until the maximum level of the block was achieved and at 5 min subsequently. The time for first analgesic requirement postoperatively or the time when the patient perceived pain for the first time following spinal anaesthesia was noted. Pain was assessed, using VAS (visual analogue scale) hourly for 24 hours. The complications such as hypotension, bradycardia, nausea, vomiting, shivering, and headache were recorded and treated accordingly.

\section{STATISTICALANALYSIS}

The study data was presented as mean $\pm \mathrm{SD}$, number and percentage. All the categorical data will be compare by using chi square test. Continuous variables in two groups were compared by $\mathrm{t}$ - test. The $\mathrm{p}-$ value $<0.05$ was considered significant.

\section{RESULTS}

In this study total of 60 patients who underwent lower limb surgery were enrolled and randomly divided into two groups. The baseline characteristics of the patients of both groups are shown in Table 1. The mean age (years) weight $(\mathrm{kg})$, height $(\mathrm{cm})$, and BMI $\left(\mathrm{kg} / \mathrm{m}^{2}\right)$ were $38.73 \pm 9.14$ and $36.87 \pm 9.04 ; 60.00 \pm 5.99$ and $59.73 \pm 7.48$; $164.20 \pm 6.40$ and $165.13 \pm 7.21 ; 22.66 \pm 1.47$ and $22.56 \pm 2.56$ in group $\mathrm{B}+\mathrm{M}$ and group $\mathrm{B}+\mathrm{D}$, respectively. The frequencies of male was $21(70 \%)$ and $17(56.67 \%)$. Total $22(73.33 \%)$ in group $\mathrm{B}+\mathrm{M}$ and 21 $(70.0 \%)$ in group $\mathrm{B}+\mathrm{D}$ had ASA physical status. The baseline characteristics such as age (yrs), weight $(\mathrm{kg})$, height $(\mathrm{cm})$, BMI, sex and ASA physical status were not significantly different in between both groups.

Table 1: Baseline characteristics of the both groups patients

\begin{tabular}{|c|c|c|c|c|c|}
\hline \multirow{2}{*}{ Characteristics } & \multicolumn{2}{|c|}{$\begin{array}{c}\text { Group B+M } \\
(\mathbf{n = 3 0})\end{array}$} & \multicolumn{2}{c|}{$\begin{array}{c}\text { Group B+D } \\
(\mathbf{n = 3 0})\end{array}$} & p value \\
\cline { 2 - 5 } & Mean & \pm SD & Mean & \pm SD & \\
\hline Age (yrs) & 38.73 & 9.14 & 36.87 & 9.04 & 0.430 \\
\hline Weight $(\mathrm{kg})$ & 60.00 & 5.99 & 59.73 & 7.48 & 0.879 \\
\hline Height $(\mathrm{cm})$ & 164.20 & 6.40 & 165.13 & 7.21 & 0.598 \\
\hline BMI $\left(\mathrm{kg} / \mathrm{m}^{2}\right)$ & 22.66 & 1.47 & 22.56 & 2.56 & 0.853 \\
\hline Sex & & & & & \\
\hline Males & 21 & $70.00 \%$ & 17 & $56.67 \%$ & 0.422 \\
\hline Females & 9 & $30.00 \%$ & 13 & $43.33 \%$ & \\
\hline ASA physical status & & & & & \\
\hline I & 22 & $73.33 \%$ & 21 & $70.00 \%$ & 0.775 \\
\hline II & 8 & $26.67 \%$ & 9 & $30.00 \%$ & \\
\hline
\end{tabular}

The characteristics of block characteristics between groups are shown in Table 2. The mean duration of onset time of sensory block at T10 (min.) was $8.57 \pm 1.96$ and $6.60 \pm 1.61$ in between group $\mathrm{B}+\mathrm{M}$ and group $\mathrm{B}+\mathrm{D}$, respectively. The mean duration to maximum sensory block level (min.) was $14.82 \pm 2.23$, and $13.53 \pm 1.53$ in between group $\mathrm{B}+\mathrm{M}$ and group $\mathrm{B}+\mathrm{D}$, respectively. The mean time in minutes for complete motor block (min.) was 19.07 \pm 2.29 and $16.57 \pm 1.50$ in between group $\mathrm{B}+\mathrm{M}$ and group $\mathrm{B}+\mathrm{D}$, respectively. The mean duration Motor Emergence from Bromage 3 (min.), Sensory Emergence and

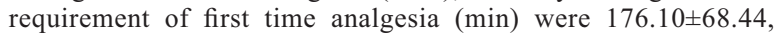
$150.43 \pm 52.48$ and $225.80 \pm 90.00$ in group $\mathrm{B}+\mathrm{M}$ and 223.67 \pm 71.37 , $199.67 \pm 53.45$ and $303.67 \pm 62.50$ in group $B+D$, respectively. The mean Onset time of sensory block at T10 (min.), Time to maximum sensory block level (min.), Time in minutes for complete motor block (min.), Time for Motor Emergence from Bromage 3 (min.), Time for Sensory Emergence and Time for first analgesia (min) were significantly different between groups.
Table 2: Comparison of block characteristics between groups

\begin{tabular}{|c|c|c|c|c|c|}
\hline \multirow{2}{*}{\begin{tabular}{c} 
Characteristics \\
\cline { 2 - 5 }
\end{tabular}} & \multicolumn{2}{|c|}{$\begin{array}{c}\text { Group B+M } \\
\mathbf{( n = 3 0 )}\end{array}$} & $\begin{array}{c}\text { Group B+D } \\
(\mathbf{n = 3 0})\end{array}$ & p value \\
\cline { 2 - 5 } & Mean & \pm SD & Mean & \pm SD & \\
\hline $\begin{array}{c}\text { Onset time of sensory block at } \\
\text { T10 (min.) }\end{array}$ & 8.57 & 1.96 & 6.60 & 1.61 & $<0.001^{*}$ \\
\hline $\begin{array}{c}\text { Time to maximum sensory } \\
\text { block level (min.) }\end{array}$ & 14.83 & 2.23 & 13.53 & 1.53 & $0.011^{*}$ \\
\hline $\begin{array}{c}\text { Time in minutes for complete } \\
\text { motor block (min.) }\end{array}$ & 19.07 & 2.29 & 16.57 & 1.50 & $<0.001^{*}$ \\
\hline $\begin{array}{c}\text { Time for Motor Emergence } \\
\text { from Bromage 3 (min.) }\end{array}$ & 176.10 & 68.44 & 223.67 & 71.37 & $0.011^{*}$ \\
\hline Time for Sensory Emergence & 150.43 & 52.48 & 199.67 & 53.45 & $0.001^{*}$ \\
\hline Time for first analgesia (min) & 225.80 & 90.00 & 303.67 & 62.50 & $<0.001^{*}$ \\
\hline
\end{tabular}

$*=$ Significant $(\mathrm{p}<0.05)$

Table 3 shows the comparison of observed complication in both the groups during pre and post-operative duration. The frequencies of Hypotension, Bradycardia, Nausea, Vomitting and Shivering were $16.67 \%, 10.00 \%, 6.67 \%, 0.00 \%$, and $6.67 \%$ in group $\mathrm{B}+<\mathrm{M}$ and group $\mathrm{B}+\mathrm{D}$, respectively. The incidences of these complications were comparable in between both the groups.

Table 3: The comparison of observed complication in both the groups during pre and post-operative duration

\begin{tabular}{|c|c|c|c|c|c|c|}
\hline \multirow{2}{*}{ Complications } & \multicolumn{2}{|c|}{ Group B+M } & \multicolumn{2}{|c|}{ Group B+D } & Chi-square & p-Value \\
\cline { 2 - 6 } & $\mathbf{n}$ & $\mathbf{\%}$ & $\mathbf{n}$ & $\mathbf{\%}$ & & \\
\hline Hypotension & 5 & 16.67 & 2 & 6.67 & 0.64 & 0.421 \\
\hline Bradycardia & 3 & 10.00 & 7 & 23.33 & 1.08 & 0.299 \\
\hline Nausea & 2 & 6.67 & 3 & 10.00 & 0.22 & 0.640 \\
\hline Vomiting & 0 & 0.00 & 0 & 0.00 & - & - \\
\hline Shivering & 2 & 6.67 & 5 & 16.67 & 0.64 & 0.421 \\
\hline
\end{tabular}

The perioperative haemodynamic such as heart rate, systolic blood pressure (SBP) and diastolic blood pressure (DBP) are shown in Fig. 1, Fig. 2 and Fig. 2. The mean heart rate, SBP and DBP of the patients were recorded at various time intervals, such as preoperatively, at 5 min intervals for first $30 \mathrm{~min}$ then $10 \mathrm{~min}$ intervals for $60 \mathrm{~min}$ and 15 min intervals up to $180 \mathrm{~min}$. The heart rate was significantly lower in group $\mathrm{B}+\mathrm{D}$ as compared to group $\mathrm{B}+\mathrm{M}$ at perioperative 20 min. to 120 min. Moreover, the SBP and DBP were comparable during perioperative periods in between groups

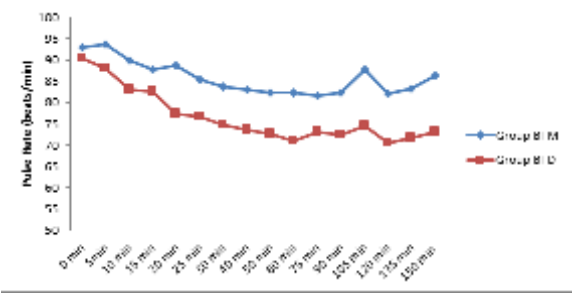

Fig. 1: Heart rate (beats/min.) at various time intervals in between groups

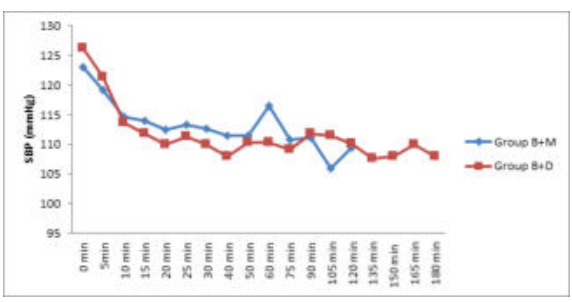

Fig. 2: SBP(mmHg) at various time intervals in between groups

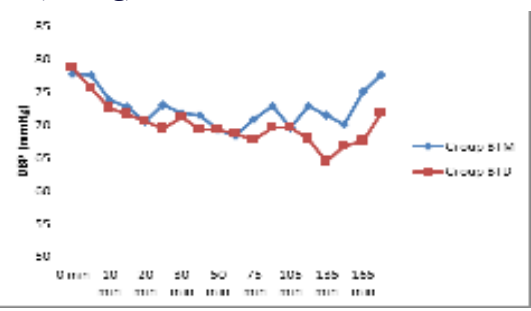

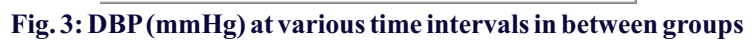




\section{DISCUSSION}

In humans, wide range of dose $(1.5-2 \mu \mathrm{g} / \mathrm{kg})$ of epidural dexmedetomidine is used. Previously various studies used $2 \mu \mathrm{g} / \mathrm{kg}$ to $1.5 \mu \mathrm{g} / \mathrm{kg}$ to epidural dexmedetomidine for postoperative analgesia $[16,17]$. Shahi et al. (2014) used smaller dose of $0.5 \mu \mathrm{g} / \mathrm{kg}$ of dexmedetomidine as an adjuvant to $14 \mathrm{ml}$ of $0.5 \%$ epidural bupivacaine, significantly extended the motor and sensory block both [18].

In this study we observed that the mean time for onset of both sensory and motor block were significantly earlier in dexmedetomidine group as compared to magnesium sulfate group. Similarly, Jain et al., (2020) reported that the onset time of sensory and motor block were significantly earlier in dexmedetomidine $(5 \mu \mathrm{g})$ group as compared to magnesium sulfate $(75 \mathrm{mg}$ ) [19]. Our study was also supported by various previous studies in which they reported that the onset time of sensory block was significantly lower in dexmedetomidine group as compared to intrathecal magnesium [18,20-22]. Wapang et al. (2014) and Deepa et al. (2017) also reported the similar finding, they reported that the mean onset time of sensory and motor block were significantly faster in dexmedetomidine group as compared to magnesium group $[23,24]$. Shukla et al. (2011) shows that the motor block was significantly lower in dexmedetomidine ( $3.96 \pm 0.92 \mathrm{~min})$ as compared to to magnesium group took $(7.18 \pm 1.38 \mathrm{~min})$ with bupivacaine [21]. Previous other studies also find the similar results, they reported that the onset of sensory and motor block was quicker in intrathecal dexmedetomidine $(10 \mu \mathrm{g})$ as compared to magnesium with hyperbaric bupivacaine [25-27]. The delayed onset of action in magnesium group may be due to alteration in $\mathrm{pH}$ and baricity of bupivacaine due to addition of $\mathrm{MgSO}_{4}$.

In this study we observed that the duration of sensory as well as motor block were prolong when added dexmedetomidine and magnesium an adjuvant to intrathecal bupivacaine, but prolongation was significantly greater dexmedetomidine group as compared to magnesium group. Similarly, Jain et al. (2020) and Shukla et al. (2011) observed that the duration of sensory and motor block times were patients significantly longer in dexmedetomidine group as compared to magnesium group $[19,21]$. Our study was also supported that Makhni et al. (2017), they reported that the sensory as well as motor block were significantly more in dexmedetomidine group as compared to magnesium group [20].

In our study the requirement of first rescue analgesia was significantly delay in dexmedetomidine as compared to magnesium group. Similar finding was observed by various previous studies, in which they reported that the mean duration of requirement of first rescue analgesia was significantly prolonged in dexmedetomidine group as compared to magnesium group [19,20,28-30]. In present study, both groups were haemodynamically stable. We did not observe any significant difference in complications such as hypotension, bradycardia, nausea, vomitting and shivering presented in Dexmedetomidine group and magnesium group.

\section{CONCLUSION}

In this study we find that the dexmedetomidine as an adjuvant with hyperbaric bupivacaine leads to earlier onset and prolonged duration of both sensory and motor block and also prolonged the duration of analgesia with negligible hemodynamic changes and side effects as compared to magnesium sulfate as an adjuvant with hyperbaric bupivacaine in spinal anesthesia.

\section{REFERENCES}

1. Sirvinskas E, Laurinaitis R. Use of magnesium sulphate in anesthesiology. Med 2002;38:147-50

2. Schultz AM, Werba A, Ulbing S. Perioperative thoracic epidural analgesia for thoracotomy. Eur J Anaesthesiol. 1997; 14:600-3

3. Kehlet H. Acute pain control and accelerated postoperative surgical recovery. Surg Clin North Am. 1999;79:431-43.

4. Bradshaw BG, Liu SS, Thirlby RC. Standardized perioperative care protocols and reduced length of stay after colon surgery. J Am Coll Surg. 1998;186:501-6.

5. Kehlet H, Mogensen T. Hospital stay of 2 days after open sigmoidectomy with a Kehlet H, Mogensen T. Hospital stay of 2 days after open si
multimodal rehabilitation programme. Br J Surg. 1999:86:227-30.

6. Shukla D, Verma A, Agarwal A, Pandey HD, Tyagi C. Comparative study of intrathecal dexmedetomidine with intrathecal magnesium sulphate used as adjuvants to bupivacaine. J Anaesthesiol Clin Pharmacol 2011;27:495-9.

7. Ozalevli M, Cetin TO, Unlugenc H, Guler T, Isik G. The effect of adding intrathecal magnesium sulphate to bupivacaine-fentanyl spinal anaesthesia. Acta Anaesthesiol Scand 2005;49:1514-9.

8. Khalili G, Janghorbani M, Sajedi P, Ahmadi G. Effects of adjunct intrathecal magnesium sulphate to bupivacaine for spinal anaesthesia: a randomized, double-blind trial in patients undergoing lower extremity surgery. J Anesth 2011;25:892-897.

9. Jabalameli M, Pakzadmoghadam SH. Adding different doses of intrathecal magnesium sulphate for spinal anaesthesia in the cesarean section: a prospective double blind

\section{randomized trial. Adv Biomed Res 2012;1:7.}

10. Kathuria B, Luthra N, Gupta A, Grewal A, Sood D. Comparative efficacy of two different dosages of intrathecal magnesium sulphate supplementation in subarachnoid block. JClin Diagn Res 2014; 8:GC01-GC05.

11. Parker RK, Connelly NR, Lucas T, Serban S, Pristas R, Berman E, et al. Epidural clonidine added to a bupivacaine infusion increases analgesic duration in labor without adverse maternal or fetal effects. J Anesth 2007:21:142-7.

12. Szumita PM, Baroletti SA, Anger KE, Wechsler ME. Sedation and analgesia in the intensive care unit: Evaluating the role of dexmedetomidine. Am J Health Syst Pharm 2007;64:37-44

13. Sule A, Anis A, Gulnaz A. Dexmedetomidine as an adjunct to epidural analgesia after abdominal surgery in elderly intensive care patients: A prospective, double-blind, clinical trial. Curr Therap Res 2008;69:16-28.

14. Kalso EA, Pöyhiä R, Rosenberg PH. Spinal antinociceptive by dexmedetomidine, a highly selective 2-adrenergic agonist. Pharmacol Toxicol 1991;68:140-3.

15. Savola M, Woodley J, Kending J, Maze M. Alpha2B adrenoreceptor activation inhibit nociceptor response in the spinal cord of the neonatal rat. Eur J Pharmacol 1990;183:740.

16. Fukushima K, Nishimi Y, Mori K, Takeda J. Effect of epidurally administered dexmedetomidine on sympathetic activity and postoperative pain in man. Anesth Analg 1996;82:S121.

17. Maroof M, Khan SA, Jain D, Khan RM, Maroof SM. Evaluation of effect of dexmedetomidine in reducing shivering following epidural anesthesia. Anesthesiology 2004; 101:A495

18. Shahi V, Verma AK, Agarwal A, Singh CS. A comparative study of magnesium sulfate vs dexmedetomidine as an adjunct to epidural bupivacaine. J Anaesthesiol Clin Pharmaco 2014;30:538-42

19. Jain K, Sethi SK, Jain R. Comparison of efficacy of intrathecal dexmedetomidine and magnesium sulfate as an adjuvant to $0.5 \%$ hyperbaric bupivacaine in patients undergoing infraumbilical surgeries under spinal anesthesia. J NTR Univ Health Sc 2020;9:116-23

20. Makhni R, Attri JP, Jain P, Chatrath V. Comparison of Dexmedetomidine and Magnesium Sulfate as Adjuvants with Ropivacaine for Spinal Anesthesia in Infraumbilical Surgeries and Postoperative Analgesia. Anesth Essays Res. 2017;11:206210.

21. Shukla D, Verma A, Agarwal A, Pandey HD, Tyagi C. Comparative study of intrathecal dexmedetomidine with intrathecal magnesium sulfate used as adjuvants to bupivacaine. JAnaesthesiol Clin Pharmacol. 2011;27:495-9.

22. Naithani U, Meena MS, Gupta S, Meena K, Swain L, Pradeep DS. Dose-dependent effect of intrathecal dexmedetomidine on isobaric ropivacaine in spinal anesthesia for abdominal hysterectomy: Effect on block characteristics and hemodynamics. Anaesthesiol Clin Pharmacol. 2015;31:72-9.

23. Wapang A, Singh NR, Singh SS, Nado H, Fatima N. Effect of intrathecal dexmedetomidine and magnesium sulphate on the characteristics of bupivacaine spinal block-a comparison. Int J Health Sci Res 2014;4:169-77.

24. Deepa G, Narayanan VK. An experimental study comparing intrathecal dexmedetomidine with intrathecal magnesium sulphate as bupivacaine adjuvants for spinal anesthesia in major gynaecological surgery. J Evolution Med Dent Sci 2017;6:1133-42

25. Sunil BV, Sahana KS, Jajee PR. Comparison of dexmedetomidine, fentanyl and magnesium sulfate as adjuvants with hyperbaric bupivacaine for spinal anesthesia: A double blind controlled study. Int J Recent Trends Sci Technol. 2013;9:14-9.

26. Al-Ghanem SM, Massad IM, Al-Mustafa MM, Al-Zaben KR, Qudaisat IY, Qatawneh $\mathrm{AM}$, et al. Effect of adding dexmedetomidine verses fentanyl to intrathecal bupivacaine on spinal block characteristics in gynecological procedures: A double blind controlled study. Am J Appl Sci. 2009;6:882-7.

27. Malleeswaran S, Panda N, Mathew P, Bagga R. A randomised study of magnesium sulphate as an adjuvant to intrathecal bupivacaine in patients with mild preeclampsia undergoing caesarean section. Int J Obstet Anesth. 2010;19:161-6.

28. Mahendru V, Tewari A, Katyal S, Grewal A, Singh MR, Katyal R. A comparison of intrathecal dexmedetomidine, clonidine, and fentanyl as adjuvants to hyperbaric bupivacaine for lower limb surgery: A double blind controlled study. J Anaesthesiol Clin Pharmacol. 2013;29:496-502.

29. Gupta R, Bogra J, Verma R, Kohli M, Kushwaha JK, Kumar S. Dexmedetomidine as an intrathecal adjuvant for postoperative analgesia. Indian J Anaesth. 2011;55:347-51.

30. Al-Mustafa MM, Abu-Halaweh SA, Aloweidi AS, Murshidi MM, Ammari BA, Awwad $\mathrm{ZM}$, et al. Effect of dexmedetomidine added to spinal bupivacaine for urological procedures. Saudi Med J. 2009;30:365-70. 